\title{
Pemanfaatan Banner Bekas sebagai Tas Belanja Layak Pakai
}

\author{
Oleh : \\ Retno Wulan Sekarsari ${ }^{1)}$, Ahmad Siboy ${ }^{2)}$ \\ ${ }^{1)}$ Fakultas Imu Administrasi, Universitas Islam Malang, \\ ${ }^{2)}$ Fakultas Hukum, Universitas Universitas Islam Malang \\ E-mail : sekarsari@unisma.ac.id ${ }^{1)}$, siboysalman@yahoo.com ${ }^{2)}$
}

\begin{abstract}
Abstrak
Hampir di setiap sudut jalan kita temui berbagai macam banner terpasang. Dan apabila masa waktunya telah habis maka banner tersebut akan dicopot dan dibersihkan oleh petugas yang berwenang yaitu Satpol PP. Banner-banner bekas di Kota Malang sangat banyak dan tidak difungsikan kembali. Banner tersebut menumpuk di gudang penyimpanan di kantor Satpol PP Kota Malang dan tidak difungsikan kembali. Dari segi komposisi bahan, banner cukup bagus untuk dimanfaatkan/didaur ulang kembali menjadi barang yang lebih bermanfaat jangka panjang. Maka kami sebagai pengabdi berniat untuk memanfaatkan banner bekas tersebut menjadi barang yang berguna serta dapat dimanfaatkan dalam jangka waktu yang panjang, yaitu menjadi sebuah tas belanja.

Tahapan pelaksanaan kegiatan Pemanfaatan Banner Bekas sebagai Tas Belanja Layak Pakai adalah sebagai berikut: (1) Peninjauan Lokasi oleh Tim Pengabdi, untuk meninjau banner bekas yang ada di kantor Satpol PP Lota Malang. (2) Penyusunan Rencana Usulan Kegiatan (RUK) dengan melibatkan seluruh tim pengabdian dan seluruh mitra, termasuk Satpol PP Malang. (3) Pengambilan Banner bekas di kantor Satpol PP Kota Malang untuk di proses menjadi sebuah tas belanja. (4) Penyortiran, dan pembersihan banner, mencuci dan menjemur semua banner bekas yang layak untuk diproses menjadi tas belanja layak pakai. (5) Membuat pola tas, memotongan banner, dan menjahitnya menjadi tas belanja layak pakai untuk dibagikan ke masyarakat Kota Malang. (6) Menghias tas belanja dari banner bekas dengan menggunakan renda, kain flanel, dan aksesoris agar cantik dan menarik. (7) Pembangian tas belanja dari banner bekas kepada masyarakat Kota Malang dan kantor Satpol PP Kota Malang.
\end{abstract}

Kata Kunci: Banner, Banner Bekas, Tas Belanja.

\section{Pendahuluan}

Salah satu bentuk pengabdian kepada masyarakat adalah praktek lapangan. Dalam hal ini khususnya bidang lingkungan, perlu kita ketahui bahwa keadaan lingkungan di berbagai wilayah di Indonesia kini telah tercemar sampah/limbah plastik. Sampah kian hari makin menumpuk karena masih kurangnya kesadaran masyarakat untuk memanfaatkan dan mengolah kembali sampah/limbah tersebut. Jika ini dibiarkan terjadi maka akan terjadi penumpukan sampah dimana-mana. Diawali dari pemikiran tersebut, kami sebagai pengabdi ingin menyelesaikan permasalahan tersebut lebih lanjut.

Kota Malang merupakan kota yang berpenduduknya sangat padat. Dan hal ini berbanding lurus dengan jumlah sampah yang dihasilkan produktifitas sehari-hari, tak terkecuali "baner". Hampir disetiap sudut jalan kita temui berbagai macam banner terpasang. Banner tersebut memiliki jangka waktu tertentu untuk dipublish. Dan apabila 
- Banyaknya tumpukan limbah Banner Bekas di kantor Satpol PP Kota Malang

- Terjadinya Pencemaran lingkungan (pencemaran tanah dan pencemaran udara) karena pemusnahan limbah Banner di kantor Satpol PP Kota Malang

- Tidak dimanfaatkannya limbah Banner Bekas di kantor Satpol PP Kota Malang untuk dijadikan benda yang bermanfaat dan bisa digunakan kembali.

Dengan dimanfaatkannya limbah banner bekas untuk menjadi sebuah tas belanja layak pakai diharapkan akan meningkatkan daya minat masyarakat untuk memakai tas belanja yang lebih ramah lingkungan dan mengurangi jumlah sampah/limbah plastik kantong belanja khususnya di Kota Malang.

\section{b) Sasaran Kegiatan}

Sasaran kegiatan pengabdian kami yang berjudul "PEMANFAATAN

\section{BANNER BEKAS SEBAGAI TAS} BELANJA LAYAK PAKAI" ini adalah untuk seluruh masyarakat Kota Malang terutama yang membutuhkan tas belanja guna membantu kegiatan sehari-hari.

\section{c) Mitra Kegiatan}

Adapun mitra kegiatan dalam projek ini adalah :

- Satuan Polisi Pamong Praja Kota Malang, sebagai penyedia banner bekas yang akan didaur ulang menjadi tas belanja layak pakai. 


\section{Jurnal Abdiraja}

ISSN : 2621-9379 (Online)

Volume 4, Nomor 1, Maret 2021

- Penjahit, yang akan membantu pengabdi dalam pembuatan tas dari Banner bekas

- Mahasiswa, yang akan membantu pengabdi dalam melaksanakan pengabdian ini, yang berjumlah lima orang.

\section{d) Pembentukan Tim Teknis/Korlap}

Tim teknis dibentuk oleh Ketua tim Pengabdian Masyarakat, yang berisikan Wakil dan tim mahasiswa UNISMA yang beranggotakan lima orang.

\section{Hasil Dan Pembahasan}

Pelaksanaan kegiatan ini merupakan bentuk keberlanjutan dari pelaksanaan kegiatan pengabdian yang telah dilaksanakan di Kantor Satpol PP Kota Malang.

Tabel. 1: Peralatan Kegiatan dan Bahan untuk Membuat Tas Belanja Dari Banner Bekas

\begin{tabular}{|c|l|}
\hline No. & Peralatan/Bahan \\
\hline 1. & Kamera \\
\hline 2. & Gunting \\
\hline 3. & Alat Tulis \\
\hline 4. & Lem Tembak \\
\hline 5. & Kain Flanel \\
\hline 6. & Manik-manik \\
\hline 7. & Benang dan Mesin Jahit \\
\hline 8. & Accessoris \\
\hline 9. & Sikat untuk mencuci Banner \\
\hline 10. & Sabun untuk mencuci Banner \\
\hline 11. & Tali tampar untuk menjemur \\
\hline 12. & Paku dan Palu \\
\hline
\end{tabular}

Tahapan pelaksanaan kegiatan

\section{PEMANFAATAN BANNER BEKAS} SEBAGAI TAS BELANJA LAYAK

PAKAI adalah sebagai berikut:

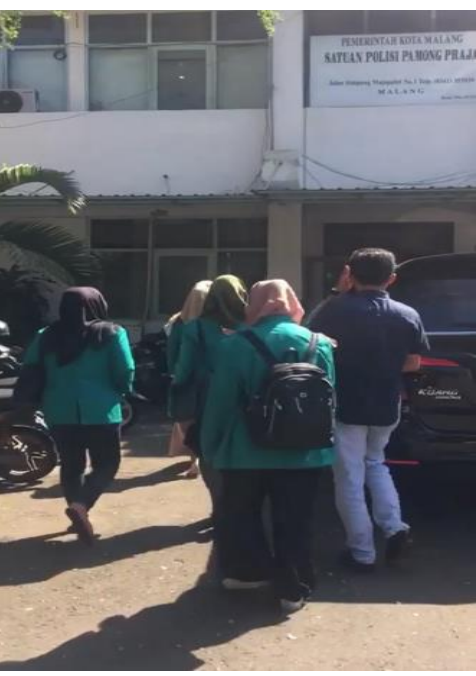

Gambar 1: Peninjauan Lokasi oleh Tim Pengabdi, untuk meninjau banner bekas yang ada di kantor Satpol PP Lota Malang.

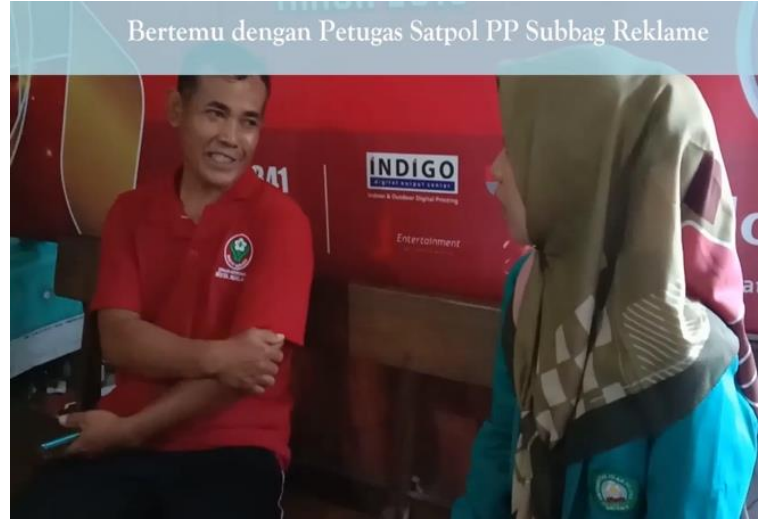

Gambar 2: Penyusunan Rencana Usulan Kegiatan (RUK) dengan melibatkan seluruh tim pengabdian dan seluruh mitra, termasuk Satpol PP Malang. 


\section{Jurnal Abdiraja}

ISSN : 2621-9379 (Online)

Volume 4, Nomor 1, Maret 2021

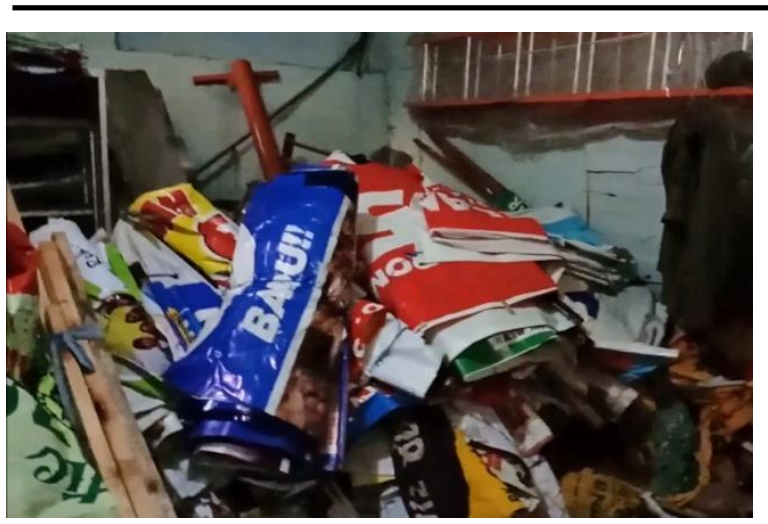

Gambar 3: Pengambilan Banner bekas di kantor Satpol PP Kota Malang untuk di proses menjadi sebuah tas belanja.
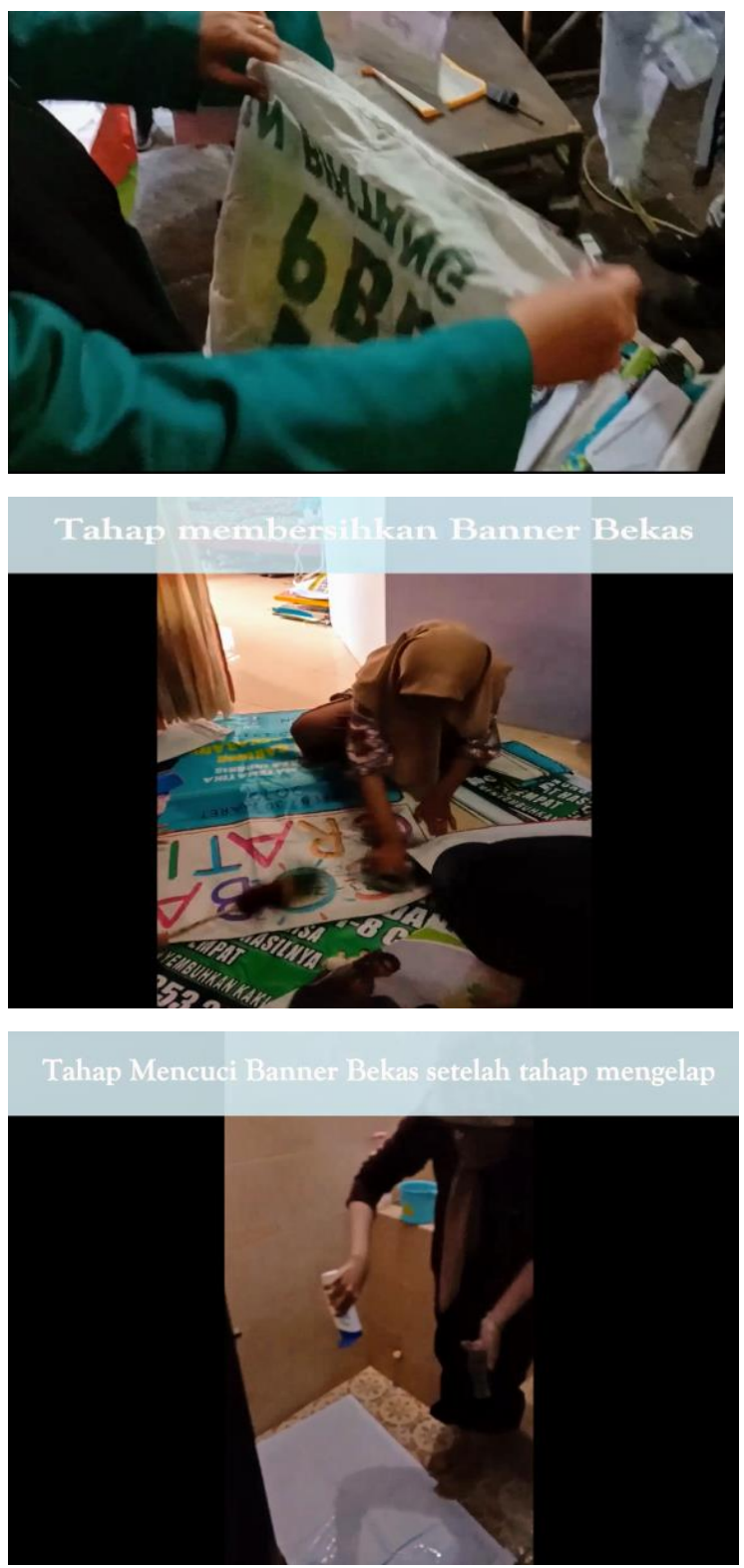

Gambar 4: Penyortiran, dan pembersihan banner, mencuci dan menjemur semua banner bekas yang layak untuk diproses menjadi tas belanja layak pakai.
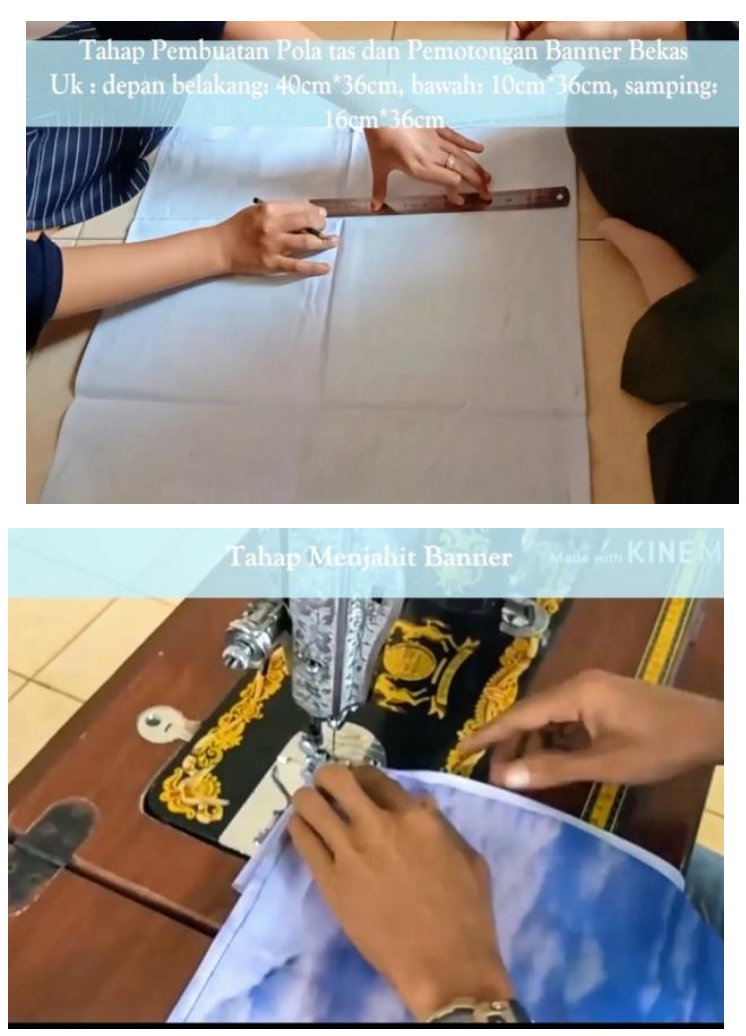

Gambar 5: Membuat pola tas, memotongan banner, dan menjahitnya menjadi tas belanja layak pakai untuk dibagikan ke masyarakat Kota Malang.
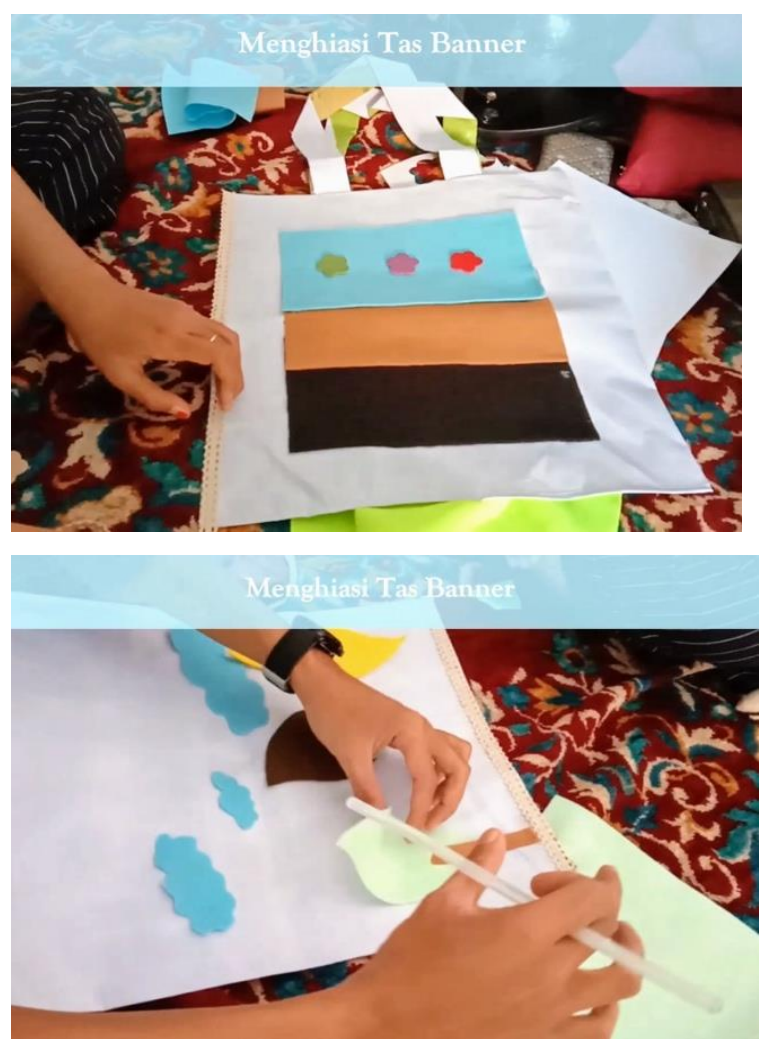

Gambar 6: Menghias tas belanja dari banner bekas dengan menggunakan renda, kain 


\section{Jurnal Abdiraja}

ISSN : 2621-9379 (Online)

Volume 4, Nomor 1, Maret 2021

flanel, dan aksesoris agar cantik dan menarik.

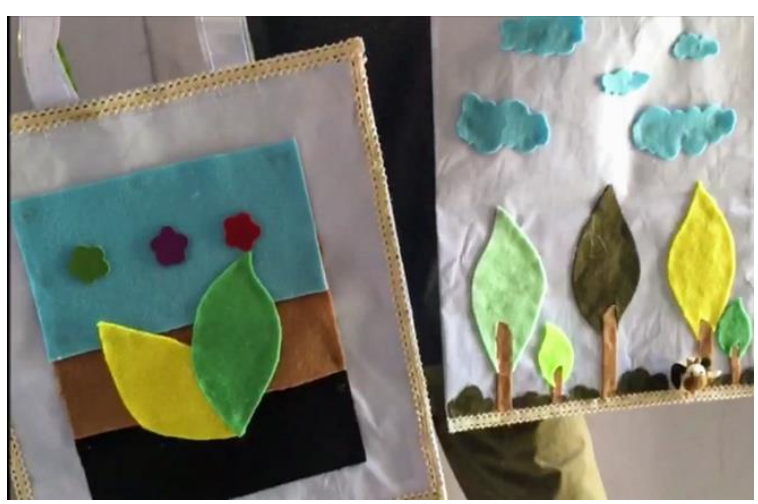

Gambar 7: Beberapa contoh tas dari banner bekas yang sudah jadi, dan siap dibagikan kepada masyarakat Kota Malang.
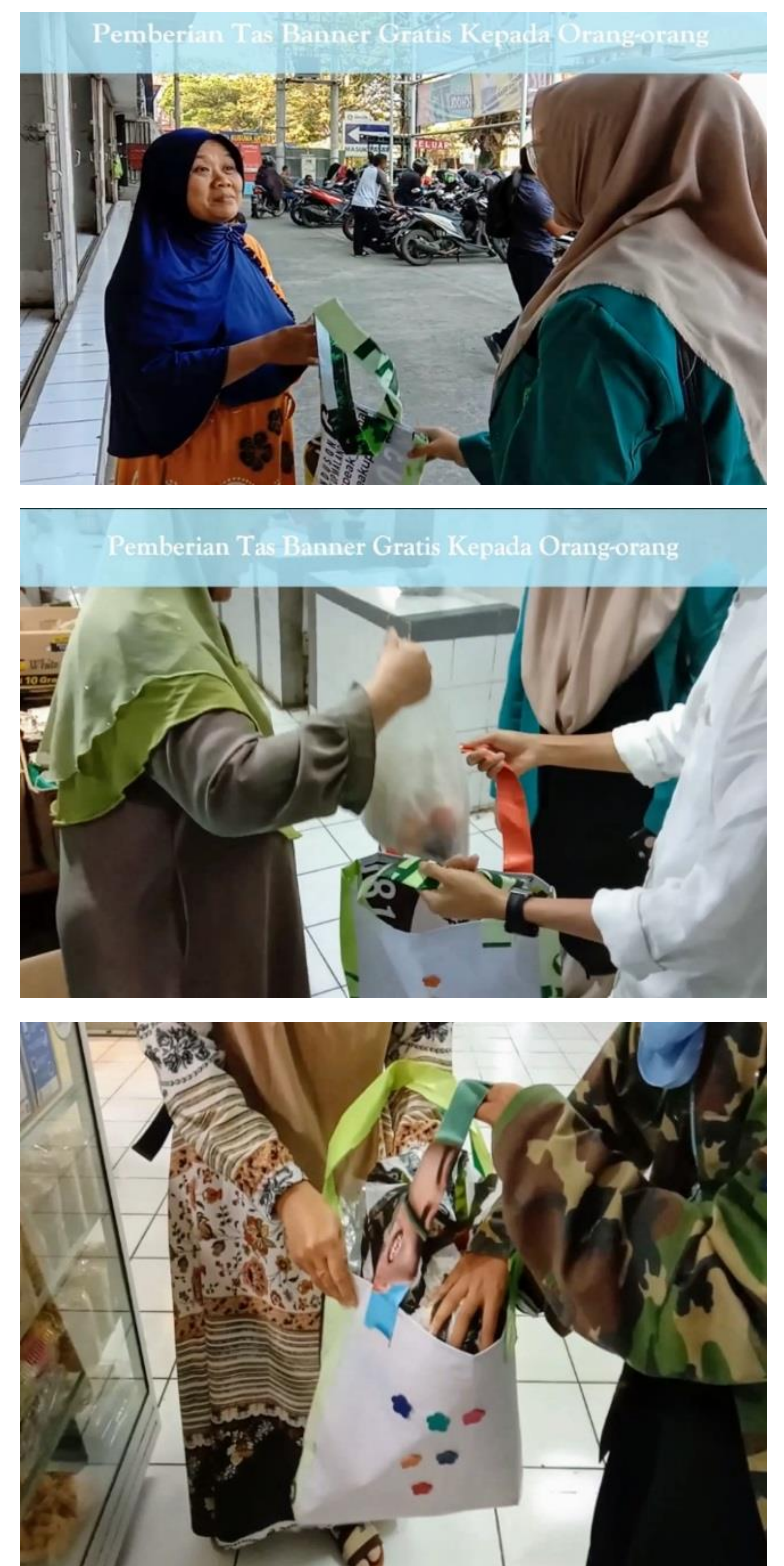

Gambar 8: Pembangian tas belanja dari banner bekas kepada masyarakat Kota Malang dan kantor Satpol PP Kota Malang.

\section{Kesimpulan}

Kegiatan pengabdian kepada masyarakat dengan mitra Satpol PP Kota Malang telah dilaksanakan dengan baik. Dampak perubahan dari kegiatan ini adalah berkurangnya pencemaran tanah dan pencemaran udara yang dikarenakan penimbunan banner bekas dan pembakaran banner bekas. Selain itu sampah/limbah banner juga berkurang drartis karena diolah dan dimanfaatkan kembali menjadi tas belanja. Dengan menggunakan tas belanja dari banner bekas, masyarakat terhidar dari penggunaan kantong plastik belanja sekali pakai. Penggunaan tas belanja dari banner bekas juga berkontribusi mengurangi jumlah limbah plastik kantong belanja sekali pakai di kota Malang.

\section{Ucapan Terima Kasih}

Atas terlaksananya dengan baik kegiatan Pengabdian Masyarakat Hibah Internal UNISMA ini disampaikan terima kasih kepada semua Tim Pengabdi:

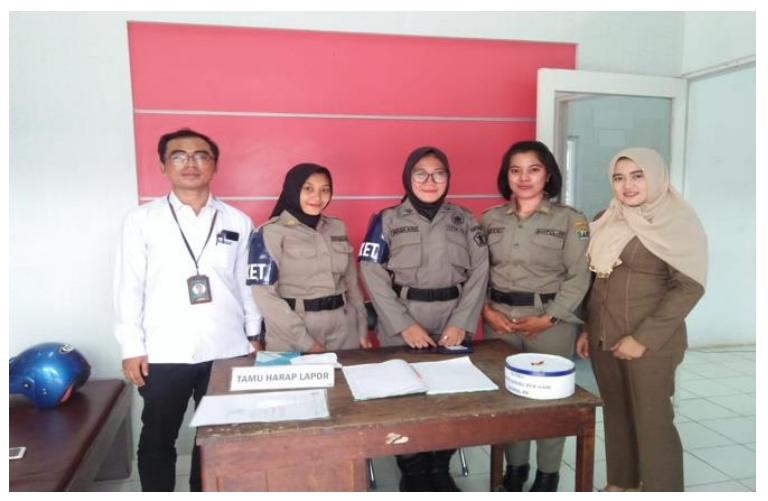




\section{Jurnal Abdiraja}

ISSN : 2621-9379 (Online)

Sumodiningrat, G. (1999). Pemberdayaan Masyarakat dan Jaring Pengaman Sosial Jakarta: Gramedia.

Syahyuti, (2006). 30 Konsep Penting dalam Pembangunan Pedesaan dan Pertanian. Jakarta: Bina Rena Pariwara.

\section{Daftar Pustaka}

Agusta, I. (2007). Aneka Metode Partisipasi Untuk Pembangunan Desa. Blogspot http://iagusta.blogspot.com/.

Sosiolog Pedesaan Institut Pertanian Bogor. Diakses, 2 November 2007.

Cathart, R.S., and Larry A. Samovar, (1974). Small Group Communication : A Reader. New York : Holt, Rinehart and Winston, Inc.

Chamala, R.S., (1995). Overview of Participative Action Approaches in Australian Land and Water Management. Dalam Chamala, S. and Keith, K. (eds), 1995.

Khairuddin, (2000). Pembangunan Masyarakat., Tinjauan Aspek: Sosiologi, Ekonomi dan Perencanaan. Liberty, Yogyakarta. 


\section{Jurnal Abdiraja}

ISSN : 2621-9379 (Online)

Volume 4, Nomor 1, Maret 2021 